El destino de sol y playa en España para el turismo chino: una perla oculta aún por descubrir

Spanish sun and beach destinations and Chinese outbound tourism: a hidden gem waiting to be discovered

\title{
Yin Li
}

Universidad Rey Juan Carlos sofia_1212@163.com

https://orcid.org/0000-0002-1710-8275

Recibido/Received: 30-03-2020

Aceptado/Accepted: 25-05-2020

\section{RESUMEN}

España es uno de los principales destinos turísticos del mundo. Su extensión en costas, así como la variedad y calidad de sus playas ha provocado que estas se consideren desde hace décadas uno de los recursos turísticos más importantes, atrayendo a turistas de todo el mundo cada año. Sin embargo, este producto parece ser ignorado por los turistas chinos. ¿Es cierto que a los chinos no les gustan las playas? ¿Cómo atraer a más turistas chinos a los litorales españoles? Estas son cuestiones que merece la pena indagar y debatir. Como consecuencia de ello, basándonos en el análisis sobre productos turísticos ofrecidos por agencias de viajes chinas, así como una encuesta dirigida a turistas chinos, se puede inferir que a los turistas chinos no les desagrada el turismo de sol y playa, sino que carecen de suficiente información y conocimiento sobre este producto. Consideramos, por lo tanto, que el turismo de sol y playa español de cara al mercado chino posee un considerable potencial que hay que desarrollar. El objetivo de este artículo, resultado de la observación y reflexión sobre el particular, es aprovechar de manera efectiva y adecuada de los recursos de sol y playa de España para atraer a turistas chinos, promoviendo el desarrollo económico de las zonas turísticas que, además, es un tema importante para la industria turística española. En este sentido, hacemos unas propuestas prácticas a través de la cooperación empresarial, la mejora de instalaciones y servicios, y campañas de promoción bien diseñadas para aprovechar los recursos españoles de sol y playas y abrirlos al mercado emisor chino.

Palabras claves: turismo; sol y playa; España; turistas chinos

\section{ABSTRACT}

Spain is listed among the top tourist destinations in the world, and its beautiful coastlines and beaches have long been regarded as one of its most significant tourist resources, attracting millions of tourists from around the world every year. However, these popular attractions seem to be ignored by Chinese tourists, despite the considerable rise in Chinese tourist numbers over the past decade. The aim of this article is to account for the under-representation of visitors from China in Spain and to identify strategies to promote Spanish beach tourism among this demographic. Based on an analysis of the tourist products offered by Chinese tourist agencies and a survey of Chinese tourist behaviours and motivations, the results reveal that Chinese 
tourists do not dislike beach tourism, but do lack information about and awareness of beach tourism products in Spain. The article concludes with a series of practical proposals for cooperation within the industry to improve facilities and services, and well-designed marketing campaigns to harness the full potential of Spanish coastal tourist destinations and open them up to the growing Chinese outbound tourism market.

Keywords: tourism; sun and beach; Spain; Chinese tourists

\section{CÓMO CITAR ESTE ARTÍCULO/ HOW TO CITE THIS ARTICLE}

Li, Yin (2021): El destino de sol y playa en España para el turismo chino: una perla oculta aún por descubrir. Rotur, Revista de Ocio y Turismo, 15(1): 151-169 https://doi.org/10.17979/rotur.2021.15.1.6133

\section{INTRODUCCIÓN}

Como segundo país turístico del mundo, además de sus monumentos históricos y culturales, las playas y el sol son recursos turísticos muy importantes para España e incluso con los términos "Sol y Playa" se puede identificar parte del país (Yepes Piqueras, 1999), especialmente uno de sus productos turísticos más solicitados en temporada estival. Con sus numerosas costas de clima templado, bien mediterráneo o bien atlántico, y soleado en su mayor parte, las playas españolas son un destino favorito de vacaciones. Aunque, según el estudio elaborado por Mabrian Technologies (2018), el interés de este tipo de turismo está decayendo en los últimos años, sigue siendo una de las principales razones por las que los turistas extranjeros vienen a España ${ }^{1}$.

Sin embargo, las playas españolas no parecen ser un destino elegido por los viajeros chinos. Algunos estudios señalan que esta oferta turística no les resulta muy atractiva, a diferencia de los turistas occidentales. Con el desarrollo económico de China en las últimas tres décadas, cada vez más chinos viajan al extranjero, y la contribución de turistas chinos a la industria turística española también se ha incrementado. Sería útil que las autoridades, organismos relacionados con el turismo y los profesionales españoles desarrollaran planes específicos de promoción para generar interés sobre este modelo de turismo entre los viajeros chinos. Especialmente en los últimos años, la disminución de turistas ingleses y alemanes, junto con la recuperación de otros países competidores mediterráneos, tales como Turquía, Egipto y Túnez (Mabrian Technologies, 2019), da a España la oportunidad de considerar nuevos mercados emisores para su turismo litoral, y el mercado chino podría ser una opción potencial importante.

El objetivo de este artículo, resultado de la observación y reflexión sobre el particular, es aprovechar de manera efectiva y adecuada de los recursos de sol y playa de España para atraer a turistas chinos, promoviendo el desarrollo económico de las zonas turísticas que, además, es un tema importante para la industria turística española.

Este estudio está basado no solo en la observación y toma de datos, sino también en el análisis de los productos turísticos ofrecidos por las agencias de viajes chinas y los datos resultantes de encuestas, para comprender por qué los turistas chinos no se adhieren al modelo del turismo de sol y playa español.

Por otro lado, como aplicación práctica surgida tras la observación y análisis de datos, sugerimos propuestas sobre cómo promover el interés de los chinos por las playas y destinos turísticos costeros españoles.

\footnotetext{
${ }^{1}$ El estudio Mabrian Technologies ha analizado más de 55 millones de menciones turísticas referentes a 113 destinos turísticos de toda España, el interés por los productos de sol y playa representó 19\% en el 2018 (21\% en el 2017), situándolo en el segundo lugar, después del turismo cultual.
} 


\section{METODOLOGÍA}

Para lograr el objetivo planteado en nuestro artículo, hemos seguido el siguiente proceso metodológico: en primer lugar, hemos hecho una exhaustiva revisión bibliográfica para extraer información y datos que nos ayuden a conformar el marco teórico contextual, con el fin de proponer una aplicación práctica que consideramos podría incentivar y potenciar el turismo chino en el recurso del sol y playa español. Este trabajo se ha apoyado en datos emitidos por Turespaña y el Ministerio de Cultura y Turismo de la República Popular China, así como de diversos organismos oficiales de turismo, como China Tourism Academy (CTA) y Ctrip, el mayor proveedor chino de servicios de viaje.

En segundo lugar, hemos realizado visitas personales a los destinos litorales de España, tales como Girona y poblaciones gerundenses de la Costa Brava, así como Barcelona y sus playas urbanas; Tarragona, en la Costa Dorada; Valencia y su playa urbana de la Malvarrosa; Alicante y Benidorm, en la Costa Blanca; Málaga, en Costa del Sol; y otras ciudades litorales como Cartagena, Murcia, San Sebastián, Gijón, La Coruña y, por último, la isla de Tenerife. La observación directa es un pilar fundamental y deberá servir de material de apoyo inicial para nuestra investigación.

En tercer lugar, se han investigado y analizado los productos e itinerarios hacia España ofrecidos por cuatro de las principales agencias de viajes chinas, que son: Ctrip, Tuniu, China Youth Travel Service (CYTS) y JinJiang Travel (JJT). De este modo, podemos mejorar la comprensión del mercado emisor chino y confirmar si el turismo de sol y playa hacia España ha recibido atención profesional suficiente.

Por el último, configuramos un cuestionario y realizamos una encuesta a 451 turistas chinos para obtener una información más concreta sobre su interés por el turismo del sol y playa español, con el fin de mejorar la oferta y demanda de este recurso turístico en el mercado chino.

\section{LOS TURISTAS CHINOS AL EXTERIOR}

Con el rápido desarrollo de la economía durante los últimos diez años y el aumento de la demanda turística, China es el mayor país emisor turístico del mundo, el número de visitas al extranjero por parte de ciudadanos chinos sigue creciendo y nada indica que en los próximos años se pueda revertir esta tendencia.

Según los datos publicados por el Ministry of Culture and Tourism of the People's Republic of China $^{2}$, en el año 2018, el mercado turístico emisor de China llegó a 150 millones, un 14,5\% más que el año anterior, y el gasto turístico en el extranjero superó 130 mil millones de dólares ${ }^{3}$ (gráfico 1).

Gráfico 1: Número de turistas chinos en el extranjero 2013-2018 (millones)

\footnotetext{
${ }^{2}$ Ministerio de Cultura y Turismo de la República Popular China.

3 Entre esta cifra y la que ofrece Statista, el portal de estadísticas para estudios de mercado, se aprecia alguna inconsistencia, pues este último afirma que el gasto de turistas chinos en el extranjero llegó a 277 mil millones de dólares en 2018
} 


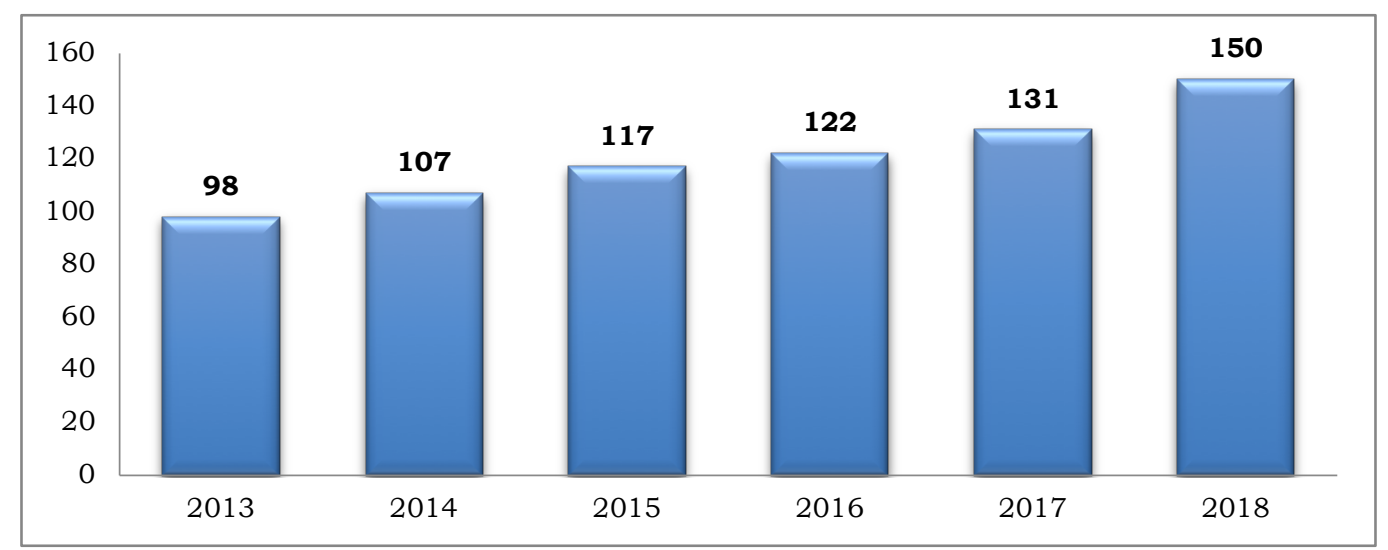

Fuente: Elaboración propia, basada en los datos de Ministry of Culture and Tourism of the People's Republic of China

Además, el interés de viajar a Europa está aumentando significativamente. Según el Informe sobre los turistas chinos que viajan a Europa basado en Big Data $2018^{4}$, publicado conjuntamente por el organismo oficial China Tourism Academy (CTA) en colaboración con Ctrip, en el año 2018, Europa fue la segunda área de destino para los turistas chinos, representando un $11 \%$ de la cuota de mercado, sólo después de Asia (gráfico 2), y el número de turistas chinos a Europa supuso un $27 \%$ con respecto al año 2017. Cabe señalar que, entre los diez destinos europeos más populares, España se situó en el séptimo puesto en 2017 y en sexto lugar en 2018, después de Rusia, Italia, Reino Unido, Alemania y Francia. Así pues, España es un destino turístico de primer orden para el mercado emisor chino, por lo que se hace necesario contemplar todos sus productos y analizar cómo aumentar la potencial clientela turística hacia dichos productos.

Gráfico 2: Destinos del mundo visitados por los turistas chinos

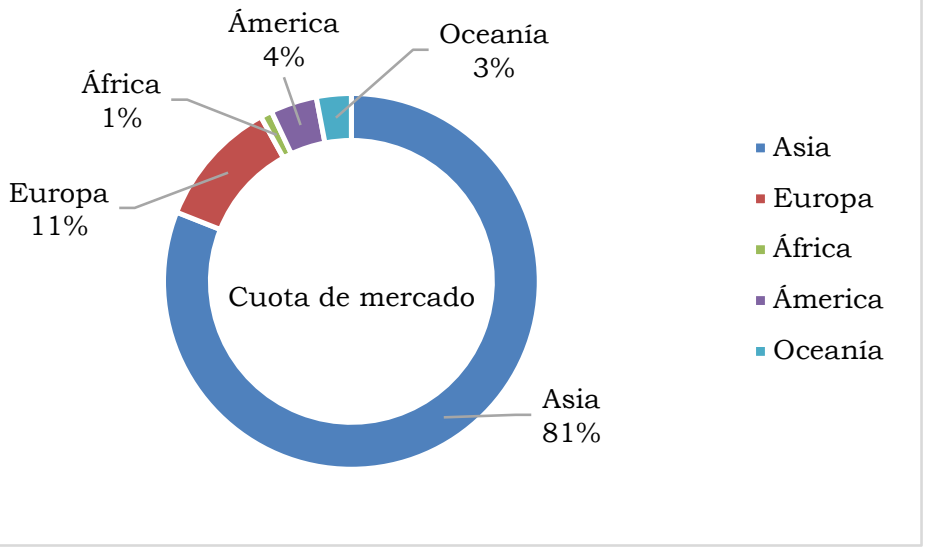

Fuente: Elaboración propia, basada en los datos que ofrecen CTA y Ctrip

\section{LOS TURISTAS CHINOS EN ESPAÑA}

\footnotetext{
${ }^{4}$ Estos datos se han publicado en China en 2019. Proporcionamos el nombre de la página en chino para, en caso de interés por parte de lectores con conocimientos de chino, puedan tener acceso a la página original. 中国游客赴欧洲旅游大数据报告(2018).

Disponible en: https://baijiahao.baidu.com/s?id=1626676445495764621\&wfr=spider\&for=pc
} 
España es el segundo destino turístico más popular del mundo ${ }^{5}$, sin embargo, hace pocos años que los chinos comenzaron a tener interés y curiosidad por viajar a España, gracias a la gran promoción turística y al intercambio cultural entre los dos países. Aunque todavía el turismo chino en España supone una baja de cuota de mercado, un 0,8\% del número total de turistas que recibió España en el 2018, poco a poco esta tendencia está cambiando.

Según los datos emitidos por Turespaña, el número total de turistas chinos a España muestra una tendencia general al alza, aunque hubo un pequeño descenso en 2016. En el año 2018, España recibió 649 mil turistas chinos, es decir, 2,5 veces más que en el año 2013 (gráfico 3).

Por otro lado, los turistas chinos tienen cada vez más poder adquisitivo, el gasto en consumo en España está creciendo considerablemente. En particular en el año 2018, el gasto total ascendió a 1.310 millones de euros, 10 veces más que en el año 2013, la cifra más alta de la historia (gráfico 4).

Gráfico 3: Número total de llegadas de turistas procedentes de china a España

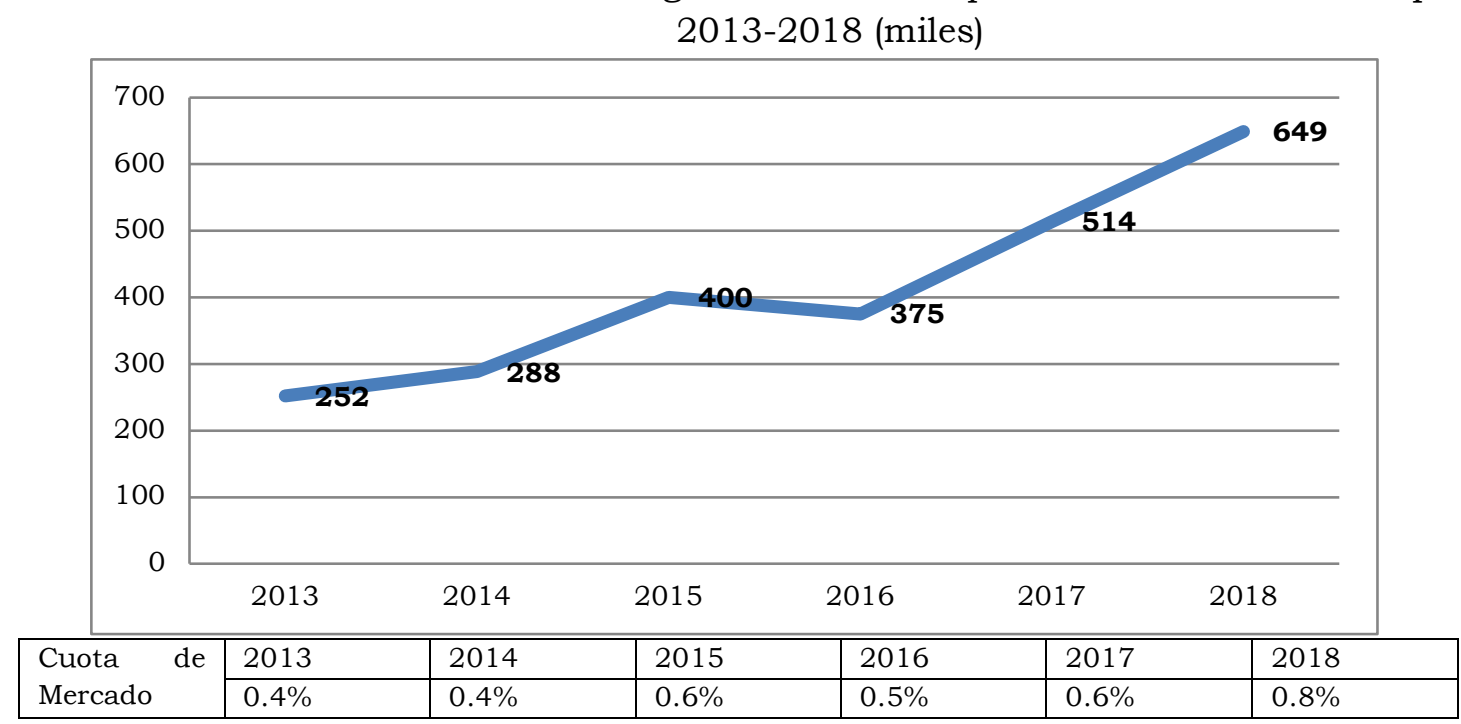

Fuente: Elaboración propia, basada en los datos que ofrece Turespaña

Gráfico 4: Gasto total de turistas procedentes de china en España 2013-2018 (millones de €)

\footnotetext{
${ }^{5}$ Raquel Villaécija citando el informe sobre competitividad en viajes y turismo 2019 publicado por el Foro Económico Mundial (WEF).
} 


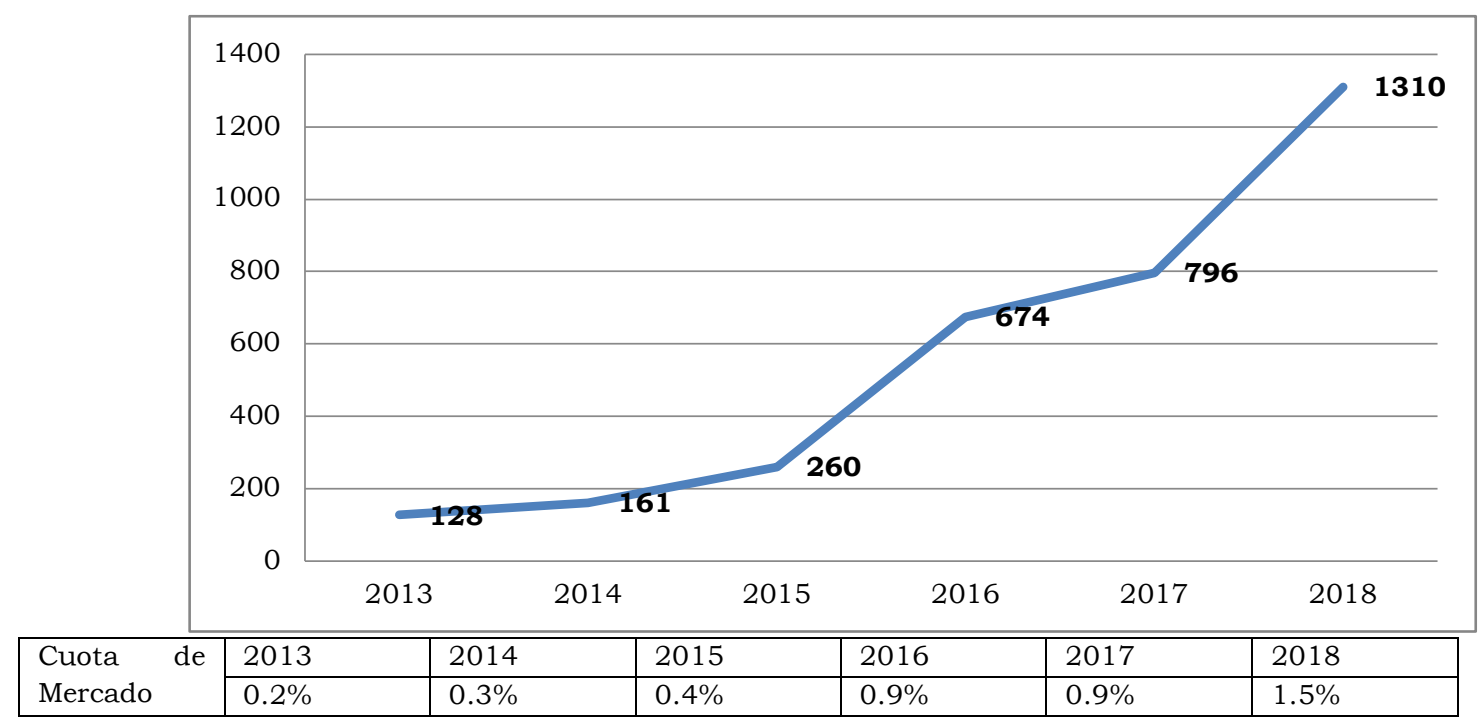

Fuente: Elaboración propia, basada en los datos que ofrece Turespaña

\section{MOTIVACIÓN DE VIAJE PARA LOS TURISTAS CHINOS A ESPAÑA}

Es cierto que los turistas chinos prefieren destinos europeos donde tengan acceso fácil a las compras, razón por la cual París, Londres y Roma atraen a más (Vizcaíno Ponferrada, 2016, p. 504). Lo mismo ocurre en España con Cataluña y la Comunidad de Madrid que siempre son los dos destinos favoritos. En 2018, el número de visitantes chinos a estas dos comunidades representaron un $46 \%$ y $32 \%$ respectivamente (Frontur, 2018).

Sin embargo, en los últimos años, en particular los jóvenes de clase media-alta y los millennials están cambiando el comportamiento en materia de consumo de los turistas chinos, prefiriendo aproximarse a la cultura y estilo de la vida locales. Según indicadores turísticos de China 2018, publicado por Turespaña, a pesar de que las compras fue la actividad principal (un 73\%), las visitas culturales y visitas a otras ciudades representó un $68 \%$ y $51 \%$ respectivamente, lo que estuvo muy cerca del porcentaje del turismo de compras.

Además, según el informe de CTA y Ctrip (2018), que hemos mencionado antes, "viajar para conocer el país" y "viajes a medida y personalizados" ya son una nueva tendencia para el turismo chino, que cada vez más busca experiencias de viaje únicas que los integren en la cultura local. De los diez temas turísticos europeos más populares para los turistas chinos en 2018, cuatro se refieren a España, gastronomía, viajar a pueblos poco conocidos, fútbol y fiestas populares (Tomatina, Fallas etc), según la tabla 1.

Tabla 1: 10 temas turísticos europeos más populares para los turistas chinos (2018)

\begin{tabular}{|c|c|c|}
\hline Top & Tema & \multicolumn{1}{|c|}{ Destino } \\
\hline 1 & Banquetes de Boda & Francia, Italia, Grecia \\
\hline 2 & Gastronomía & Italia, Alemania, España \\
\hline 3 & Esquiar & Suiza \\
\hline 4 & Experiencia ecuestre & Francia \\
\hline 5 & Visitar pueblos poco conocidos & Italia, Francia, España \\
\hline 6 & Fútbol & España, Italia \\
\hline 7 & El turismo cultural & Reino Unido, Alemania, \\
\hline 8 & Festivales destacados & Republica Checa \\
\hline 9 & Ver aurora boreal & España \\
\hline
\end{tabular}




\section{0} Civilización antigua

Grecia

Fuente: Elaboración propia, basada en los datos que ofrecen CTA y Ctrip

Por lo tanto, podemos observar que la motivación y el modelo de los chinos para visitar España está cambiando. Sin embargo, algunos recursos y productos turísticos, tales como sol y playa, espacios naturales protegidos, parques nacionales, turismo rural, etc., aún necesitan atraer su atención.

\section{EXPOSICIÓN DE RESULTADOS Y DEBATE: ¿POR QUÉ LOS CHINOS NO VIENEN A LAS PLAYAS DE ESPAÑA?}

El turismo masivo de sol y playa fue un recurso importante que impulsó el desarrollo urbanístico a lo largo de la costa mediterránea. Desde mediados del siglo XX el binomio sol y playa ha sido el principal recurso turístico español, preferido por la inmensa mayoría de los turistas nacionales y extranjeros (Maurín, 2019, p.66), especialmente para los británicos y alemanes, aunque en los últimos años está sufriendo una caída en el número de visitantes procedentes de dichos países. Sin embargo, este recurso no parece ser muy atractivo para los turistas chinos. Según los indicadores turísticos referidos al turismo emisor chino en 2018, publicados por Turespaña, los productos más solicitados para los chinos son: compras, arte y cultura, gastronomía y turismo urbano, el sol y playa tiene poca demanda ${ }^{6}$.

En España se cree que la razón principal por la que a los chinos no les gusta el turismo de sol y playa es porque prefieren mantener la piel blanca. Esta afirmación no es del todo exacta, de hecho, gran cantidad de turistas chinos viajan a las islas o a las playas del sudeste asiático, a Vietnam, Tailandia, Indonesia, Filipinas, Malasia y las Islas Maldivas (en el Océano Índico) y Saipán (el Océano Pacífico) ${ }^{7}$. Además, según la investigación del autor D. Tomás (2011, p.80), para el turismo chino no es habitual un tipo de vacaciones uni-destino, en un solo hotel y descansando una o dos semanas en la playa. Según este autor, tampoco el ocio nocturno propio de muchas zonas costeras (bares y discotecas) suele estar entre sus preferencias y conceden a este ocio un interés mínimo.

Aunque haya estudios previos que proporcionan una base teórica, para comprender por qué los turistas chinos no se adhieren al modelo de turismo de sol y playa español, consideramos ${ }^{8}$ que se debe analizar desde los dos siguientes aspectos:

$1^{\circ}$ Ofertas de las agencias de viajes chinas.

$2^{\circ}$ Opiniones de los turistas chinos, basándonos en encuestas.

Los chinos viajan cada vez más de forma independiente, pero debido a la dificultad de obtener el visado y la barrera de los idiomas, la mayoría de los turistas chinos aún viajan a Europa a través de viajes organizados por agencias. Por lo tanto, conocer las ofertas que ofrecen las agencias de viajes chinas nos ayudará a entender cómo se crea en ellos la imagen turística de España. Además, hacer la encuesta se considera como una herramienta útil para ayudarnos a comprender de manera directa las preferencias e inquietudes de los turistas chinos. A continuación, analizaremos desde estos dos siguientes aspectos el motivo por el cual los chinos no vienen a las playas españolas.

\section{VI.1. El Análisis de las ofertas de las agencias de viajes chinas}

\footnotetext{
${ }^{6}$ Las principales actividades que realizaron fueron compras (73\%), visitas culturales (68\%) y visitas a ciudades $(51 \%)$, mientras que sólo un 30\% declaró realizar actividades de sol y playa (Turespaña).

${ }^{7}$ Esto también se confirmará en la encuesta posterior.

8 Esta consideración la hacemos desde nuestra perspectiva en calidad de ciudadana china con varios años de residencia en España, precisamente para estudiar el sector turístico y los flujos de movimientos turísticos e intereses culturales recíprocos de ambas culturas cuando emprenden un viaje de Oriente a Occidente o viceversa.
} 
El Informe sobre el desarrollo del Turismo Emisor $\mathrm{Chino}^{9}$ publicado por la China Tourism Academy (CTA) indica que, en el 2018, el 55.24\% de turistas chinos viajaron fuera del país con paquetes turísticos. Cabe apuntar que el $45 \%$ de los turistas chinos que viajaron a España en 2018 recurrió a un paquete turístico, un porcentaje muy significativo, según datos de Turespaña. Por lo tanto, conocer los productos e itinerarios ofrecidos por las agencias de viajes chinas contribuye a una mayor comprensión del interés de los visitantes chinos por el turismo del sol y playa en España.

En este sentido, investigamos y analizamos los paquetes de viaje con único destino España ofrecidos por cuatro grandes empresas de viaje chinas para el mes mayo, junio y julio de 2020. Consideramos que estos tres meses son temporada alta para ir a la playa; otro motivo es que no están disponible todavía los paquetes en sus páginas webs después de julio, por lo tanto, hemos tomado la decisión de focalizar la atención en este período. Estas cuatro empresas son: Ctrip, Tuniu, China Youth Travel Service (CYTS), JinJiang Travel (JJT), en una búsqueda realizada el 25 de febrero de 2020.

España se están posicionando como destinos de turismo cultural, por lo que las agencias de viajes chinas también están dando prioridad al atractivo cultural al diseñar sus productos para viajar a España.

A través de la tabla 2, podemos observar que los paquetes ofrecidos por estas cuatro grandes agencias/proveedores de viajes chinas son parecidos, los itinerarios están diseñados para visitar ciudades grandes y sus monumentos históricos.

Tabla 2: Estadística de destinos españoles ofrecidos por agencias de viajes chinas

(25 de febrero de 2020)

\begin{tabular}{|c|c|c|c|c|}
\hline & $\begin{array}{c}\text { Ctrip } \\
\text { (total } 14 \\
\text { paquetes) }\end{array}$ & $\begin{array}{c}\text { Tuniu } \\
\text { (total } 7 \\
\text { paquetes) }\end{array}$ & $\begin{array}{c}\text { CYTS } \\
\text { (total } 2 \\
\text { paquetes) }\end{array}$ & $\begin{array}{c}\text { JJT } \\
\text { (total } 2 \\
\text { paquetes) }\end{array}$ \\
\hline Madrid (Ciudad) & 13 & 6 & 2 & 2 \\
\hline $\begin{array}{l}\text { Barcelona } \\
\text { (Ciudad) }\end{array}$ & 14 & 7 & 2 & 1 \\
\hline $\begin{array}{l}\text { Alrededores de } \\
\text { Madrid (Toledo, } \\
\text { Consuegra, } \\
\text { Segovia etc) }\end{array}$ & 5 & 6 & 2 & 2 \\
\hline $\begin{array}{l}\text { Ciudades de } \\
\text { Andalucia (Sevilla, } \\
\text { Córdoba, } \\
\text { Granada) }\end{array}$ & 7 & 6 & 2 & 2 \\
\hline $\begin{array}{l}\text { Ciudades } \\
\text { amuralladas } \\
\text { (Ronda, Mijas, } \\
\text { Cuenca, Avila) }\end{array}$ & 4 & 6 & 2 & 2 \\
\hline Destinos litorales & 4 & 4 & 1 & 1 \\
\hline Valencia (ciudad) & 4 & 3 & 0 & 1 \\
\hline
\end{tabular}

\footnotetext{
${ }^{9}$ Estos datos se han publicado en China en 2019. Proporcionamos el nombre de la página en chino para, en caso de interés por parte de lectores con conocimientos de chino, puedan tener acceso a la página original. 中国出境游发展研究报告2019. Disponible en: http://www.199it.com/archives/921618.html
} 


\begin{tabular}{|l|l|l|l|l|}
\hline $\begin{array}{l}\text { Viaje para el } \\
\text { fútbol }\end{array}$ & 1 & 0 & 0 & 0 \\
\hline Otro & 1 & 0 & 0 & 1 \\
\hline
\end{tabular}

Fuente: Elaboración propia

Barcelona y Madrid son dos destinos principales, seguidos por las ciudades de Andalucía y alrededores de Madrid. A este respecto, Aureli Lojo (2016, p.516) ya afirmaba que los turistas chinos están interesados principalmente en Barcelona, Madrid, Sevilla, Granada, Toledo, Mijas, Ronda, Córdoba y Zaragoza. Sin embargo, tanto en nuestra investigación como en la de Aureli Lojo, hay pocos paquetes turísticos que incluyan el turismo de sol y playa.

Ctrip, el mayor proveedor chino de servicios de viaje, proporciona un total de 14 itinerarios para visitar España, la mayoría para visitar Madrid y Barcelona capital, de los cuales, sólo cuatro paquetes tienen alguna relación con playas. De estos cuatro viajes, sólo un paquete está diseñado específicamente para el viaje orientado a la playa, ofreciendo tres días enteros (tres pernoctaciones) en Mallorca para que los turistas disfruten de la playa. De los tres paquetes restantes relacionados con la playa, uno permite que los turistas pernocten una noche en Alicante, pero no dispone de tiempo libre ni visitas a la playa; otros dos sólo hacen una breve parada por el litoral de la Costa Blanca sin tiempo libre ni pernoctación.

Tuniu, con cuatro paquetes relacionados con la playa, de los cuales uno ofrece tour en barco por el estrecho de Gibraltar, y otros tres pernoctan en Málaga sin tiempo libre.

China Youth Travel Service sólo ofrece una ruta programada con tiempo libre para visitar y pernoctar en Málaga.

JinJiang Travel, ofrece dos productos en España, de los cuales uno incluye itinerarios litorales sin pernoctación ni tiempo libre a Tarragona, Girona y Peñiscola, en la provincia de Castellón (popular por la serie Juego de Tronos).

A través del análisis de los paquetes turísticos ofrecidos por estas agencias de viajes chinas, se comprueba que el turismo de sol y playa de España no está entre sus principales productos y no han recibido el interés ni la atención profesional para promocionar el turismo chino hacia este segmento. De las cuatro agencias de viajes chinas, sólo Ctrip ofrece un producto específicamente diseñado para un viaje orientado a las playas de España. Es difícil esperar que estas ofertas e itinerarios programados puedan hacer una gran contribución al turismo de sol y playa. Sin embargo, esta situación también demuestra que hay un gran potencial para desarrollar.

\section{VI.2. Encuesta de turistas chinos sobre el turismo de playa en España}

Por lo que ya hemos visto, los paquetes turísticos de sol y playa que ofrecen las agencias de viajes chinas son escasos. Para obtener información más concreta y efectiva, realizamos una encuesta para averiguar por qué, siendo España un país de muchas horas anuales de sol y extensas y cuidadas playas, gran parte de ellas con bandera azul que garantiza su calidad, tiene tan poca demanda entre los turistas chinos.

Para ello, hemos realizado un total de 451 encuestas entre potenciales viajeros chinos con estudios superiores (56\%) que provienen en su mayor parte de las cuatro grandes ciudades chinas (Beijing, Shanghái, Guangzhou y Shenzhen). En el contexto de China, los turistas con dichas características tienen un poder adquisitivo medio/alto, así que tienen más posibilidad para viajar al exterior. La edad está mayoritariamente entre 30 y 39 años (28\%) y entre 50 y 59 años (27\%). El 59\% son mujeres. 
De las 451 respuestas, según el gráfico 5, un 83\% nunca ha estado en España, un $17 \%$ (76 personas) ya tenía experiencia previa; de esos, un $62 \%$ solamente una vez. Este resultado coincide con los datos emitidos por Turespaña, que mencionamos anteriormente, en el que se indicaba que, a pesar del creciente número de turistas chinos que vienen a España, la cuota de mercado es baja.

Además, nuestra encuesta también muestra que aquellos que sólo han estado en España una vez, prefirieron el viaje organizado por agencias (66\%), mientras que aquellos que han viajado a España dos o más veces, prefirieron hacerlo de forma independiente (62\%), según el gráfico 6.

Gráfico 5: Frecuencia de viaje a España

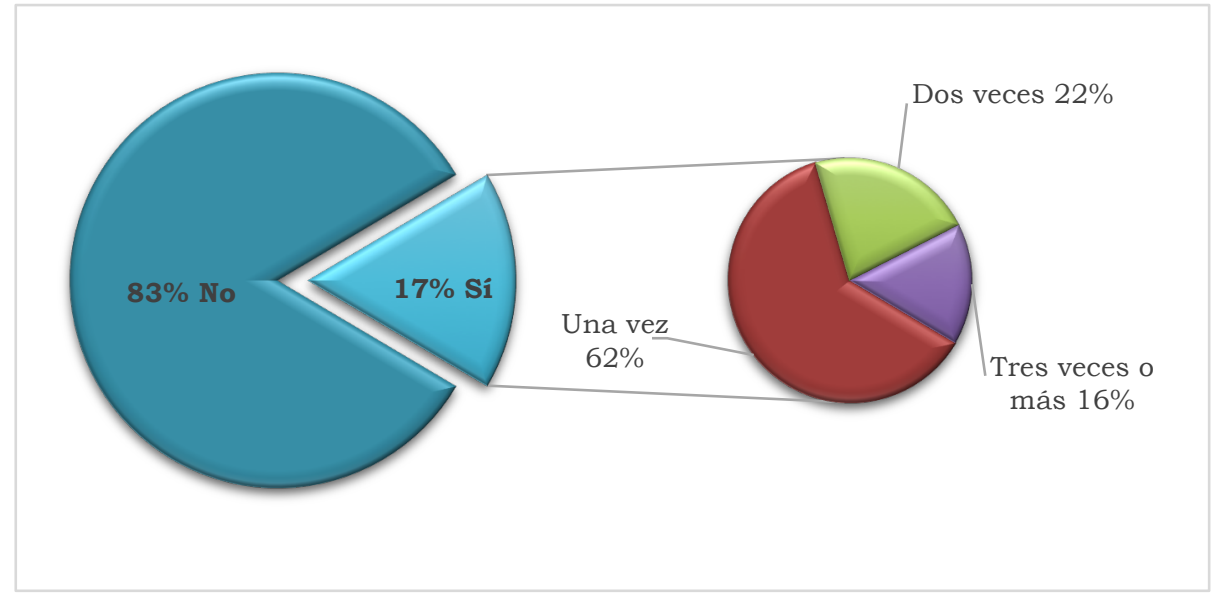

Fuente: Elaboración propia

Gráfico 6: Forma de viaje (76 encuestados $\left.{ }^{10}\right)$

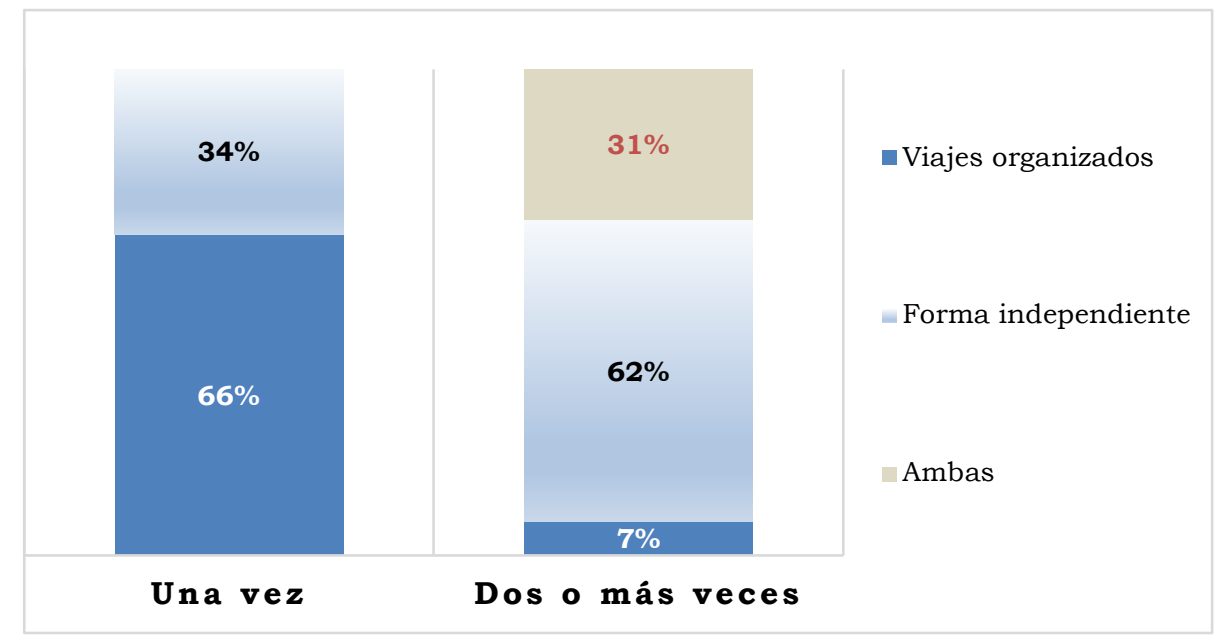

Fuente: Elaboración propia

En cuanto a la pregunta “¿Qué imagen le sugiere España?", los toros y el flamenco fue la repuesta mayoritaria. Entre 451 encuestados, un 65\% eligieron esta opción. Seguidos por la cultura y arte (47\%). Paisajes, fútbol y gastronomía también muestran valores significativos. Vale la pena señalar que la opción de compras, a pesar de que sigue asociándose a España, en esta encuesta sólo 37 personas (8\%) eligieron esta opción, bastante inferior a otras investigaciones turísticas. Se observa un reciente y lento cambio en los intereses de los chinos cuando visitan España. En

\footnotetext{
${ }^{10}$ La repuesta se limita a las 76 personas que respondieron "si”" en la pregunta anterior.
} 
cuanto a la opción objeto de este artículo, sólo 95 chinos (21\%) asocian España con el turismo de sol y playa, según el gráfico 7 .

Gráfico 7: La imagen de España para los chinos (respuesta múltiple)

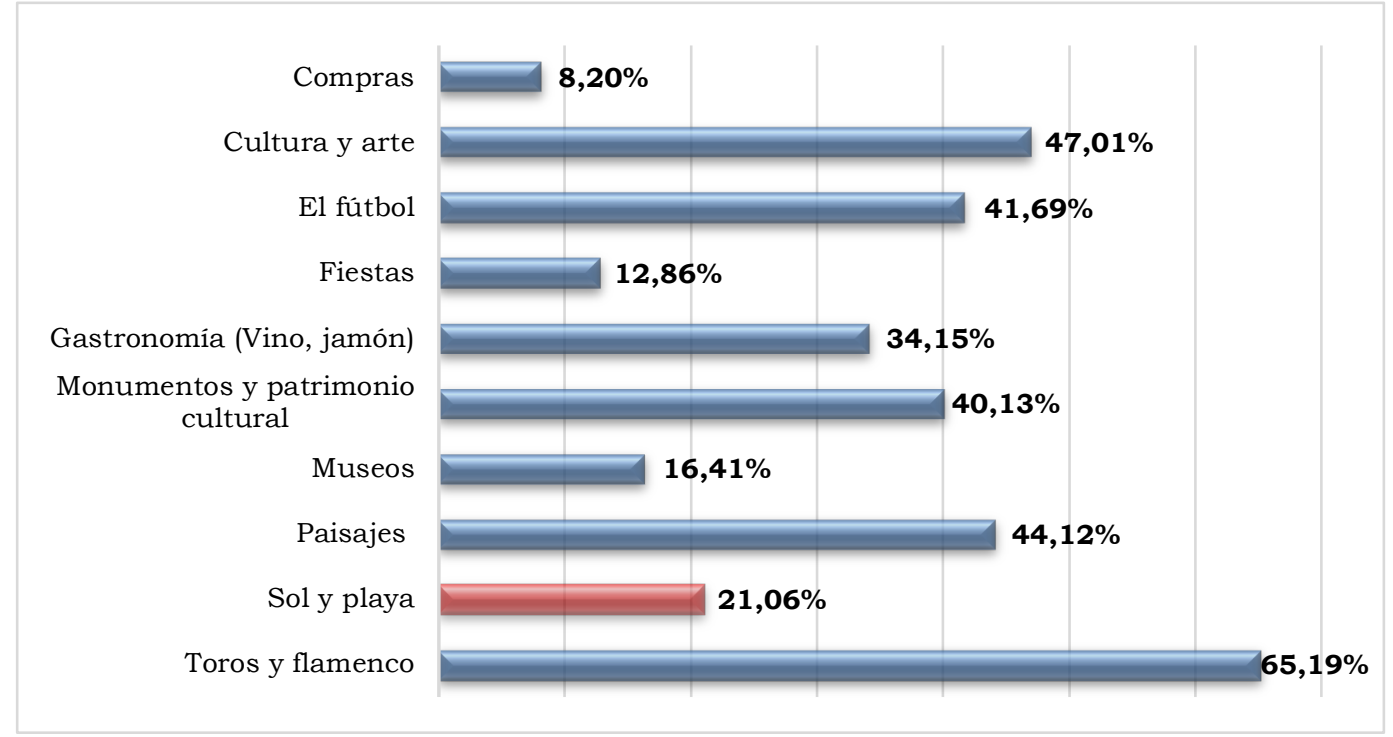

Fuente: Elaboración propia

Aunque los chinos no asocian el sol y playa como la principal imagen de España, no significa que no les interese este producto turístico. A través del gráfico 8 , podemos observar que un $89 \%$ de encuestados indican que les gusta viajar a la playa o islas, y sólo $11 \%$ no tienen interés.

Gráfico 8: ¿A los chinos les gusta el turismo de sol y playa?

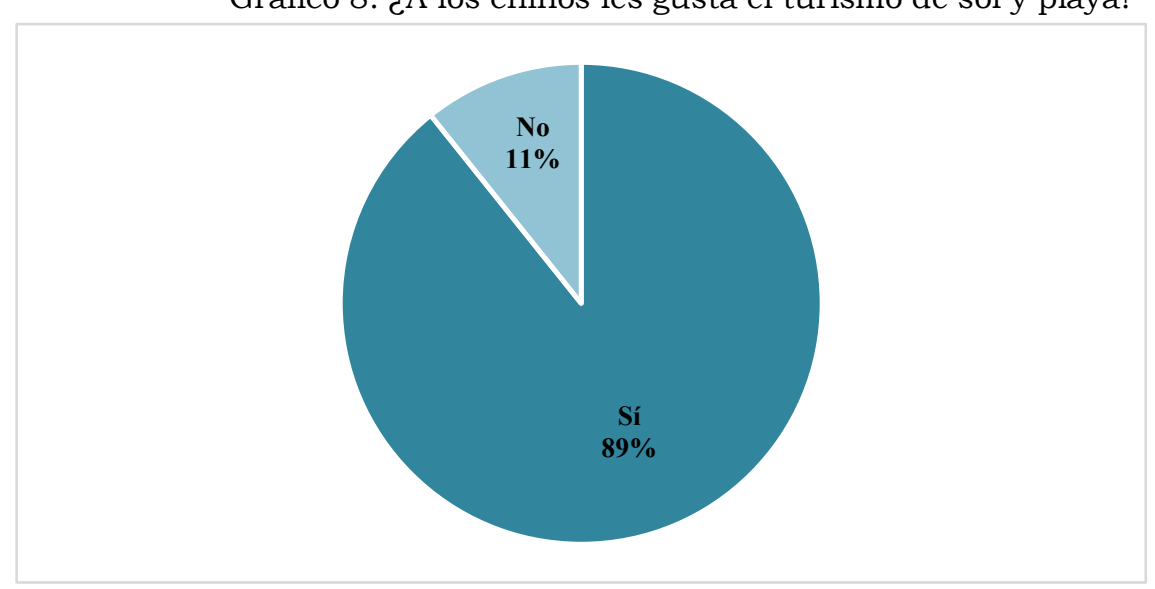

Fuente: Elaboración propia

Entonces, dado que a un gran porcentaje de los turistas chinos les gusta el turismo de sol y playa, ¿a qué países van? A través del análisis de los datos de la encuesta (gráfico 9), se ve que las Maldivas y Hawái están a la cabeza entre todos los destinos litorales, 220 encuestados (55\%) eligieron la primera, y 200 personas (50\%) la segunda. Seguidos por los países del Sudeste de Asia (46\%), tales como Vietnam, Tailandia, Filipinas, Malasia. La proximidad geográfica, los precios competitivos, no requerir visado. etc., son los motivos por los que prefieren el turismo de sol y playa de estos destinos. Sin embargo, sólo 91 encuestados (23\%) consideran a España y concretamente las islas Baleares y Canarias como uno de los destinos de interés. Lo mismo ocurre con Italia, Francia y Grecia en esta encuesta, representando también un valor bajo. Es probable que la imagen que los chinos tienen de Europa sea principalmente cultural, artística, 
paisajistica y de compras, en especial para aquellos que viajan por primera vez, el turismo del sol y la playa por el momento, no es una opción.

Gráfico 9: ¿Cuáles son los destinos de sol y playa más populares para los chinos? (respuesta múltiple, 402 encuestados $^{11}$ )

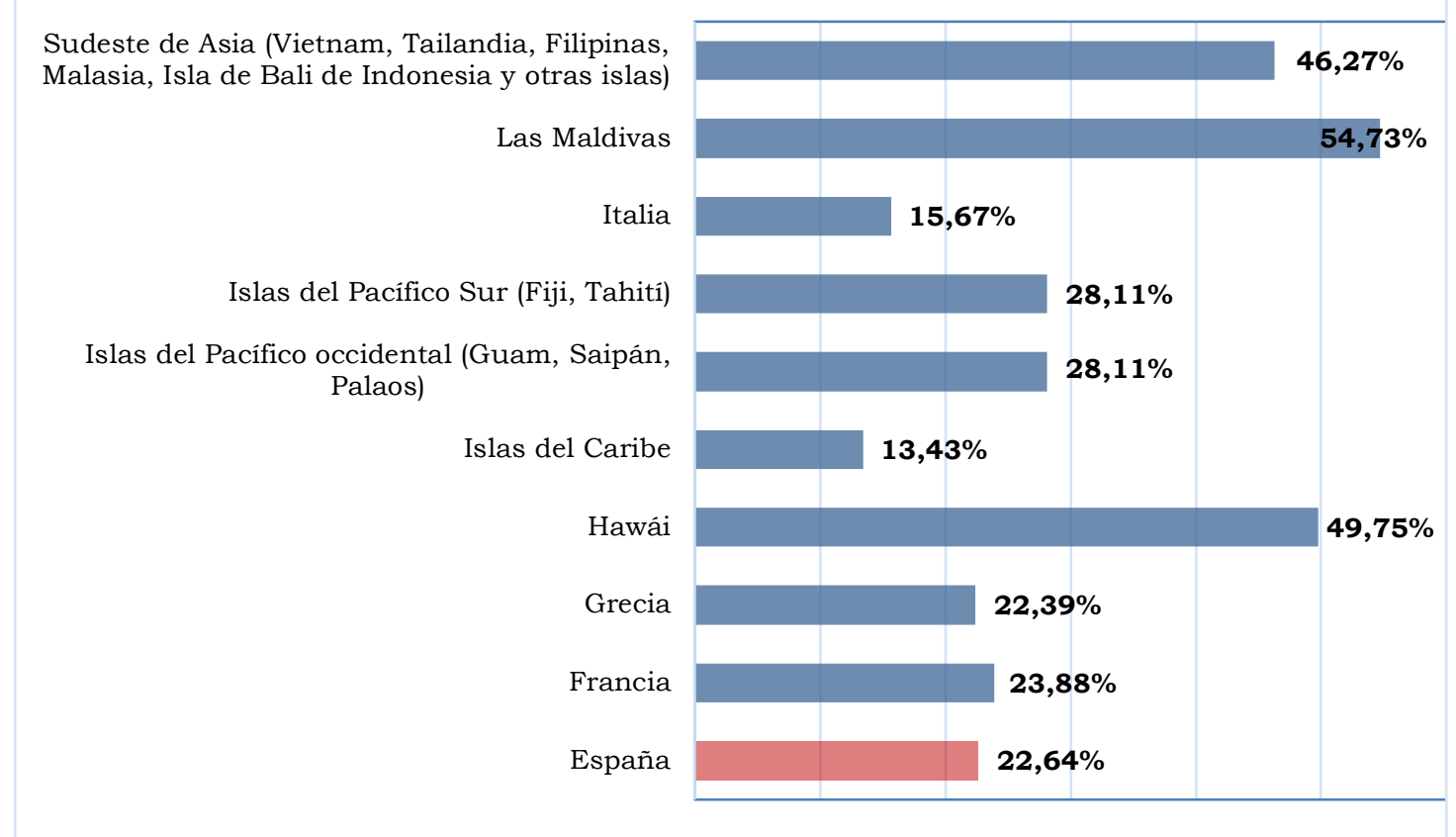

Fuente: Elaboración propia

Los factores por los que los turistas chinos no eligen España como principal destino de sol y playa (gráfico 10), podemos ver que, sorprendentemente con respecto a la opción de "larga distancia", 188 encuestados (60\%) indican desconocimiento de esta oferta turística.

Cabe señalar que la opción "bronceado" sólo fue rechazado por 16 encuestados chinos (5\%). Curiosamente los españoles piensan que la principal motivación por la que los chinos no se interesan por el sol y playa, es para evitar broncearse.

Además, 54 encuestados (17\%) piensan que en España hay muchos otros lugares de interés prioritario y 51 personas (16\%) indican que no les gusta el modelo tradicional del turismo de playa, a saber, simplemente nadar y tomar el sol y esperan tener otras atracciones complementarias.

Las "limitaciones de visado" también es un factor importante que reduce las posibilidades y disposición de los turistas chinos para viajar a España. Las restricciones de emisión de los visados afectan a la programación y duración de los viajes y por lo tanto la opción playa no está entre sus prioridades.

En cuanto al "precio", es nuestra debilidad frente al mercado chino, ya que no podemos competir con los países del sudeste asiático.

${ }^{11}$ La respuesta se limita a las 402 personas que respondieron "sí" en la pregunta anterior. 
Gráfico 10: Principales factores con los que el turista chino no eligen España como destino del turismo de sol y playa (respuesta múltiple, 311 encuestados ${ }^{12}$ )

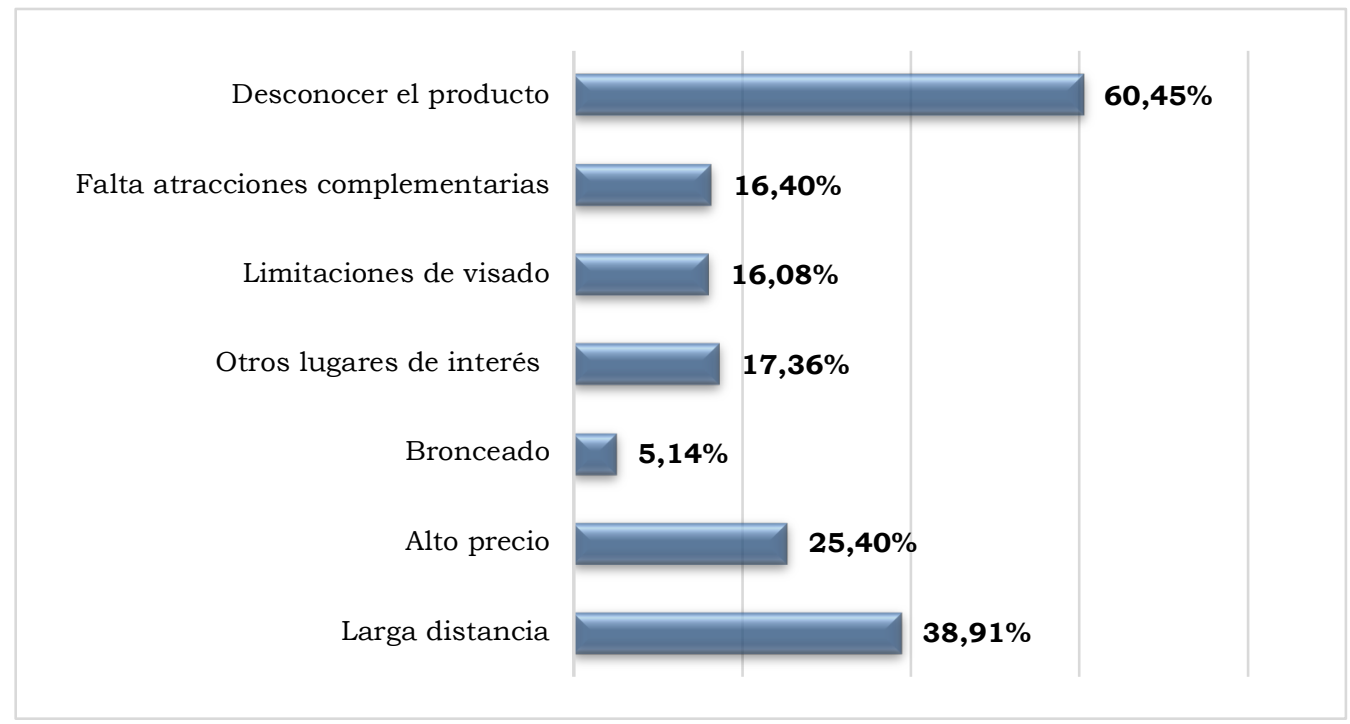

Fuente: Elaboración propia

A través del análisis de datos de nuestra encuesta, observamos que el turismo de sol y playa de España tiene mucho potencial de desarrollo en el mercado chino.

La opinión generalizada entre los españoles del miedo de los turistas chinos al bronceado no es el motivo fundamental para no visitar las playas. Por el contrario, la razón más importante es el desconocimiento de este producto turístico, que puede explicarse por la escasez de promociones, además de por la larga distancia.

La falta de atracciones complementarias, dificultad con el visado y otros lugares de interés prioritario son otros factores.

Por otro lado, el precio de la oferta de sol y playa que ofrece actualmente en España es poco competitiva para el mercado chino en comparación con los países del sudeste de Asia, en los que si hay buenas promociones.

Para ello, hacemos las siguientes propuestas prácticas para captar turistas chinos al turismo de sol y playa español.

\section{PROPUESTAS: ¿CÓMO POTENCIAR LA PRESENCIA DEL MERCADO EMISOR CHINO EN EL TURISMO DE SOL Y PLAYA ESPAÑOL?}

A través del análisis anterior, el desconocimiento y escasez de oferta son las razones fundamentales por las que los chinos no vienen a los destinos orientados al sol y la playa. Los productos e itinerarios planificados por las agencias de viajes chinas limitan que los viajeros visiten los destinos litorales. Sin embargo, se percibe un cambio en la motivación de los viajeros chinos que vienen a España y es que cada vez con mayor frecuencia buscan una experiencia más personal, lo que puede ser una oportunidad para incrementar el turismo de sol y playa. En este sentido, hacemos las siguientes propuestas y planificaciones para potenciar la presencia del mercado emisor chino en el turismo de sol y playa español.

\footnotetext{
${ }^{12}$ La repuesta se refiere a las 311 personas que no eligieron en la pregunta anterior la opción "España" como su destino
} del turismo de sol y playa. 


\section{VII.1. Aprovechar el turismo cultural para enriquecer el destino de playa}

En España, uno de los productos que han adquirido mayor relevancia en los últimos diez años es el turismo cultural (Cánoves, et al, 2016, p.432). El resultado de nuestra encuesta también muestra que la cultura, el arte y los monumentos históricos son los incentivos más importantes para que los turistas chinos vengan a España. Por lo tanto, vale la pena pensar en cómo hacer que los destinos litorales tengan a la vez función como destinos culturales.

A este respecto, los autores García Sánchez y Alburquerque García (2003, p.97) afirman que existen complementariedades crecientes entre el turismo cultural y el de sol y playa que, adecuadamente tratadas, pueden reportar beneficios para ambos tipos de destino. Muchos destinos costeros españoles se encuentran próximos a ciudades donde la cultura es su principal recurso turístico. Por ejemplo, la Costa Brava está cerca de Barcelona; la Costa del Sol andaluza, está cerca de importantes ciudades culturales como Granada, Sevilla y Córdoba, además de la propia Málaga, capital de la Costa del Sol, y que posee también un importante patrimonio cultural y museos de renombre internacional. La costa gallega tiene la ciudad cultural por excelencia, Santiago de Compostela. Aunque las ciudades mencionadas son visitadas por los turistas chinos, lamentablemente, no han mostrado interés por las costas cercanas. Por lo tanto, es necesario configurar nuevas estrategias para que estos destinos turísticos costeros lleguen a conformar un conjunto turístico que aúne playa y cultura.

A título de ejemplo, se puede aprovechar el turismo cultural de Santiago de Compostela para impulsar el desarrollo turístico en sus zonas costeras cercanas, de Pontevedra y A Coruña; o para el turismo de Cadaqués, el pintoresco pueblo costero en la Costa Brava, el museo de Salvador Dalí puede ser una inspiración. Como dicen los autores Gemma Cànoves Valiente, Josep Ma Prat Forga y Asunción Blanco Romero: el modelo de turismo litoral en España debe apostar por la reinvención y la resiliencia. La reinvención para, a partir del turismo cultural, poner en valor los territorios colindantes a los espacios litorales, y la resiliencia de los destinos para resistir y reinventarse como espacios turístico-culturales (Cánoves, et al, 2016, p. 433). Esto enriquecerá el modelo de turismo litoral tradicional de "sol y playa", será un complemento ideal para aquellos turistas con mayores inquietudes culturales. En el futuro, podemos esperar que los turistas chinos combinen el concepto de cultura con playa, permaneciendo más tiempo y diferentes estaciones del año en las costas españolas.

Por otra parte, según indica Richards en su artículo (1996, p. 26), en los últimos años, el concepto de turismo cultural ha cambiado; las distinciones entre la "alta" cultura y la "popular" comienzan a erosionarse. A medida que desaparecen estas distinciones, lo que antes era "alta cultura" (patrimonios culturales y bellas artes), ahora es la experiencia de comprender la forma de vida de una sociedad y una época. Y esto es muy atractivo para aquellos turistas chinos cada vez más exigentes, que buscan experiencias únicas de viaje, valorando considerablemente el contacto con la población local y lo integran en su cultura. En este punto, también los festivales pueden ser una buena oferta cultural complementaria para el turismo de sol y playa. En España se celebran al año más de 400 festivales que tienen gran amplitud y diversidad temática (García Sánchez y Alburquerque García, 2003, p.101), y el atractivo de estos festivales en sí mismo puede ser el motivo determinante por el que dichos turistas chinos eligen sus destinos. Por lo tanto, combinar fiestas locales, junto con la gastronomía, arquitectura, literatura y exposiciones, etc., con el turismo de playa, atraería al tipo de turista que desea experimentar más allá de un único producto, especialmente para los turistas chinos, que no están habituados a pasar una o dos semanas de vacaciones sólo en la playa, la falta actividades complementarias les resulta un turismo poco atractivo.

Estos conceptos e ideas pueden promoverse a través de varias formas de marketing, prensa, revistas, libros, TV, y los principales sitios webs relacionados con el turismo. Para hacer llegar 
toda la información al público chino, hay que aumentar la presencia en sus propias redes sociales, tales como Wechat, Sina weibo, Baidu Tieba y Tianya, etc. Además, las empresas y organismos turísticos, tales como Turespaña, deberian aumentar su presencia en los foros y ferias de turismo en Asia ${ }^{13}$, reforzando la imagen cultural de los destinos costeros tradicionales. Mediante estas estrategias, podemos agregar gradualmente más elementos culturales al turismo de playa, hasta transformar la idea actual de "sol y playa" por la de "cultura—sol y playa".

\section{VII.2. Colaborar con las agencias de viajes chinas, diseñando paquetes turisticos}

Como se ha mencionado en el análisis anterior, la mayor parte de los turistas chinos que viajan a España lo hacen a través de viajes organizados. Por lo tanto, si las agencias chinas incluyeran más destinos costeros, se contribuiría al incremento del turismo de sol y playa. Según nuestra investigación, sabemos que, al menos por el momento, los destinos españoles orientados al sol y la playa no son preferencia para los organizadores y proveedores de programas turísticos de las agencias de viaje chinas. Quizá se deba este hecho a los apretadísimos itinerarios que no permiten demasiado tiempo libre, por lo que resulta dificil que la playa sea un objetivo. Pero pensamos que hay un cierto margen potencial para desarrollar este tipo de turismo. Los destinos costeros españoles disponen de un sistema hotelero que, en su gran mayoria, tiene unos elevados estándares de calidad; por lo tanto, programar uno o dos días de tiempo libre para disfrutar de las playas y relajarse puede ser un punto interesante de los paquetes turísticos.

Además, en los últimos años, el modelo de turismo de vacaciones o "Relax" puro muestra una tendencia al alza en el mercado chino y se dirige principalmente a los destinos de países del sudeste asiático y las Maldivas. Sin embargo, aunque el modelo de sol y playa en España se caracterizó desde su primero desarrollo por una especialización orientada fundamentalmente al descanso, el reposo y la distensión (Vera, J.F. y Baños, C.J. 2010. p.339), los chinos rara vez eligen España como destino para este tipo de turismo debido a que, nuestra oferta es poco competitiva en comparación con dichos países tanto por la distancia como por el precio. Aun así, todavia tenemos la oportunidad de acceder a una parte del mercado chino. Los hoteles de ciudades costeras españoles podrian aprovechar sus ventajas de buena calidad-precio, colaborando con las agencias de viajes chinas para organizar conjuntamente paquetes turisticos, intentando lanzar un producto de vacaciones único de playa: viaje de novios, luna de miel, viajes familiares, entre otras, lo cual abriria una nueva perspectiva atractiva para el turista chino, asimismo ayudaría en gran medida a la industria hotelera y de restauración en las áreas costeras españolas.

\section{VII.3. Programas de televisión o películas como canal fundamental de promoción}

Las imágenes e información transmitida por el cine, programas de televisión o documentales tienen un gran impacto en las personas y predisponen a visitar esos lugares, no hay que subestimar esta influencia. El estudio anual TripBarometer publicado por TripAdvisor revela que un $20 \%$ de todos los encuestados chinos dijeron que la selección de sus destinos de viaje se vio muy influida por películas o programas de televisión, y este porcentaje fue aún mayor que el promedio global ${ }^{14}$ (TripBarometer, 2016, p.23).

Los lugares de rodaje de las películas o series a menudo pueden potenciar el turismo en sus áreas y atraer ingresos considerables. El ejemplo más conocido de los últimos diez años es la

\footnotetext{
${ }^{13}$ Las ferias recomendadas son: ITB Berlin, que desde hace unos años tiene una edición también en Asia; WTM de Londres (World Travel Market), IFCOT (International Forum on Chinese Outbound Tourism), COTTM (China Outbound Tourism and Travel Market), CITM (China International Travel Market), IBTM CHINA (China Incentive, Business Travel \& Meetings Exhibition), BITE (Beijing International Tourism Expo), etc.

${ }_{14}$ Según el estudio, los millennials del nivel gobal tienen más probabilidades de verse influidos por las películas y programas de televisión.
} 
serie Juego de Tronos, con una gran audiencia, que convirtió esos lugares de rodaje en destinos turísticos populares. El periodista de The Paper (Ye, 2017) escribe que, en 2016, Dubrovnik, la ciudad costera de Croacia, fue uno de los lugares de rodaje de dicha serie y recibió un 16,1\% más de turistas chinos que el año anterior. Además, el operador turístico Ctrip indica que, durante la emisión de la última temporada de esa serie, el número de turistas chinos a Croacia aumentó en un 450\% durante las vacaciones de Primero de mayo (Hou, 2019, pp.100-102).

Además de las películas, los programas de telerrealidad (o reality shows) influyen cada vez más en las opciones de los destinos de viaje. Este tipo de programas invitan a celebridades conocidas a lugares específicos para la filmación, y dichos lugares a menudo se convierten en destinos turísticos populares, en particular, entre la gente joven. Dan visibilidad a un lugar, mejoran la economía local y desarrollan el mercado turístico. Liu Wenjing (Liu 2017) afirma en su tesis que la telerrealidad tiene la ventaja de ofrecer contenido diversificado y características de la realidad, lo que puede conducir a una mayor participación y a estimular a las audiencias a ir a los destinos de rodaje. Un buen ejemplo ha sido el programa "Chinese restaurant", en el que cinco chinos famosos se unieron para abrir restaurantes en ciudades extranjeras poco conocidas por el turismo chino, pero con un alto potencial turístico. La primera temporada se filmó en Ko Chang, Tailandia; la segunda en Colmar, Francia; y especialmente la tercera temporada en 2018, después de la grabación y emisión, Taormina, Sicilia, se convirtió en un destino obligado para muchos turistas chinos, e incluso agencias de viaje tales como Ctrip, Mafengwo entre otras, también incluyeron Taormina entre sus destinos.

Los ejemplos anteriores se pueden utilizar como referencias sobre cómo atraer turismo a la costa española. En China se producen cada año gran cantidad de programas de telerrealidad, y las ciudades costeras tanto en el Mediterráneo, como en el norte y en el sur de España: Costa Brava, Costa Dorada, Costa del Azahar, Costa Blanca, Costa del Sol, costas gaditanas y onubenses, Cantabria, San Sebastián, Bayona (Pontevedra), y un largo etcétera propio de un país con tantos kilómetros de costa como España, tienen paisajes tan interesantes como los de cualquier otro país mediterráneo. Por lo tanto, los gobiernos locales españoles podrían cooperar con los canales de televisión china, para permitir grabar series o reality shows que serian muy efectivos para atraer turismo chino.

\section{VII.4. Mejorar instalaciones y servicios}

Los turistas chinos tienen su propia percepción sobre el turismo de sol y playa, es decir su comportamiento y hábitos difieren mucho de los turistas occidentales. Mientras a los primeros les interesan los paisajes, hacer fotos y probar la gastronomía en este ámbito, a los segundos, les gusta relajarse, tomar el sol, nadar y beber. El autor D. Tomás $(2011$, p.80) también observa esta diferencia de intereses y afirma que a los chinos les gusta tomarse fotografias cerca del mar, en un destino exótico, encaja con su pretensión de lograr estatus social o bien de tener unas vacaciones impregnadas de un romanticismo de estilo hollywoodiense. En consecuencia, según esta afirmación de D. Tomás, los turistas chinos podrian ser más exigentes que los turistas occidentales en cuanto a las instalaciones y servicios próximos a las playas, pues pretenderían lugares de ensueño cinematográfico.

Si esperamos llegar al mercado chino en el futuro, sería entonces necesario reforzar esos aspectos para adaptarse a las necesidades de sus clientes, por ejemplo, mejorar la calidad medioambiental del entorno, reducir la masificación turística; ofrecimiento de gastronomía de alta calidad en los hoteles, además de otros servicios complementarios muy solicitados por el turismo chino, tales como spa y masajes, tratamientos de belleza, tiendas de marcas; ofrecer actividades de deporte como el golf. Si bien todos estos son servicios que muchos hoteles costeros españoles ofrecen, especialmente los establecimientos hoteleros de mayor categoría, sí se podría pensar en 
mejorarlos para captar un mayor número de turistas con alto poder adquisitivo asiáticos, en general, y chinos, en particular. Además de ello, el colocar señales e indicadores en chino, ofrecer servicios en idioma chino, facilitar métodos de pago de China (Alipay, WeChat Pay, UnionPay QR Code), y facilitar la devolución de impuestos, sin duda contribuirían a que esos destinos españoles tuviesen un mayor atractivo para el turismo chino, que, en su mayoría, es un turista con un perfil menos estacional sobre el recurso de la playa.

\section{CONCLUSIONES}

Este artículo tiene como objetivo atraer a más turistas chinos a los litorales españoles, e intentar promover el desarrollo económico de las zonas turísticas, pero inevitablemente existen algunas limitaciones. En primer lugar, la investigación realizada para este artículo es solo un estudio preliminar sobre el turismo chino y su interés por el sol y las playas españolas, y tiene como fin, encontrar la manera de revitalizar este modelo turístico, integrando cultura y playas, mediante un marketing innovador. Todo ello merece más discusión e investigación en el futuro. En segundo lugar, hacemos una serie de propuestas prácticas, pero el proceso de implementación específico está más allá del alcance de este artículo y requiere más investigación y colaboración entre los gobiernos y autoridades relevantes. En tercer lugar, las propuestas presentadas en este artículo están dirigidas principalmente a turistas chinos, pero no se discute si también son aplicables a turistas de otros países.

El turismo es una de las mayores industrias para España y en concreto para sus destinos litorales con su principal modelo turístico de Sol y Playa, que se erige en un pilar fundamental del mercado receptor. Sin embargo, este modelo no es el preferido por el turismo chino. Esto no se debe a que a los turistas chinos no les gusten las playas, sino a que la mayoría de las agencias de viajes chinas no ofertan este tipo de paquete turístico y según nuestra encuesta los turistas chinos carecen de suficiente información y conocimiento sobre este recurso turístico.

Consideramos que si diseñamos productos y campañas de promoción atractivos, el turismo de sol y playa español de cara al mercado chino posee un considerable potencial, también para promover el desarrollo económico de las zonas.

En este sentido, este artículo propone que los profesionales turísticos, los gobiernos locales y las oficinas de turismo de las ciudades litorales españolas deberian de cooperar activamente con las agencias de viajes chinas para atraer más grupos de turistas chinos, diseñando y promoviendo itinerarios a las costas, y aumentar así la tasa de pernoctación. Al mismo tiempo, las zonas litorales también deberian mejorar sus instalaciones y servicios para proporcionar un entorno más atractivo y conveniente. Y lo más importante es que se necesitaría priorizar campañas de promoción bien diseñadas, integrando cultura-playa, junto con un buen marketing a través de las películas y programas de televisión.

\section{REFERENCIAS BIBLIOGRÁFICAS}

China Tourism Academy y Ctrip (2019). Informe sobre los turistas chinos que viajan a Europa basado en Big Data 2018. (中国游客赴欧洲旅游大数据报告2018). Recuperado de: https: / / baijiahao.baidu.com/s?id=1626676445495764621\&wfr=spider\&for=pc

China Tourism Academy (2019). El Informe sobre el desarrollo del Turismo Emisor Chino 2019 (中国出境游发展研究报告 2019). Recuperado de: http://www.199it.com/archives/921618.html 
Cánoves Valiente, Gemma; Prat Forga, Josep Ma; y Blanco-Romero, Asunción (2016). Turismo en España, más allá del sol y la playa. Evolución reciente y cambios en los destinos de litoral hacia un turismo cultural. Boletín de la Asociación de Geógrafos Españoles, 71, 431-454. Doi: $10.21138 /$ bage.2289.

García Sánchez, Antonio y Alburquerque García, Francisco Javier (2003). El turismo cultural y el de sol y playa: ¿sustitutivos o complementarios? Cuadernos de Turismo, 11, 97105. Recuperado de: https://revistas.um.es/turismo/article/view/19581

Hou, Juan (2019). Still a Gold Mine: Why the High-Cost Game of Thrones Series is still Profitable? (单集成本一亿的《权力的游戏》为何还是金矿?). China Economic Weekly, 10,100-102. Recuperado de: http://www.cnki.com.cn/Article/CJFDTotal-JJZK201910039.htm

Lojo, Aureli (2016). Turismo chino en España: un análisis del producto turístico, atracciones e itinerarios ofrecidos por agencias de viajes chinas. Cuadernos de Turismo, 37, 511517. Recuperado de: https://www.redalyc.org/articulo.oa?id=39845353011

Liu, Wenjing (2017). A Study on the Influence of Reality Show on Tourist Behavior Intention and Tourism Destination Image Perception. (真人秀对游客行为意向及旅游目的地形象感知影响研究). (Trabajo de fin de máster). Dongbei University of Finance and Economics. Recuperado de: http://cdmd.cnki.com.cn/Article/CDMD-10173-1018076544.htm

Maurín Álvarez, Manuel (2019). Los recursos turísticos, en Fernández Cuesta, Gaspar (Dir.) Atlas de Geografia Humana de España (pp.65-76). Ediciones Paraninfo, Madrid.

Mabrian Technologies (2018). Spain detaches itself from sun and beach tourism. Recuperado de: https://mabrian.com/blog/spain-stands-out-from-sun-and-beach-tourism/

Mabrian Technologies (2019). The Canary Islands affected by Turkish Competitiveness in the German market. Recuperado de: https://mabrian.com/blog/the-canary-islands-the-mainvictims-of-turkish-competitiveness /

Ministry of culture and tourism of the people's republic of china. Informe anual del mercado turístico (2013-2018). Recuperado de: http:/ /zwgk.mct.gov.cn/?classInfoId=360

Page, David (1 de febrero de 2019). España pierde casi 800.000 turistas británicos y alemanes tras cinco años de boom. El independiente. Recuperado de: https://www.elindependiente.com/economia/2019/02/01/espana-pierde-casi-800-000-

turistas-britanicos-alemanes-tras-cinco-anos-boom/

Richards, Greg (1996): Cultural Tourism in Europe. CABI, Wallingford. Recuperado de: http://www.tram-research.com/cultural_tourism_in_europe.PDF

Statista. International tourism expenditure of Chinese tourists from 2008 to 2018. Recuperado de: https://www.statista.com/statistics/249702/international-tourismexpenditure-of-chinese-tourists /

Tomás Gaimundiz, Daniel (2011). El turismo chino en España, la adaptación de destinos turísticos españoles al mercado más grande del mundo. (Trabajo de fin de máster). Universidad de Sevilla. Recuperado https://www.fundacionico.es/wpcontent/uploads/2017/08/El_Turismo_Chino_en_Espana_2.pdf

Turespaña. Fichas ejecutivas de mercados emisores: Indicadores Turísticos de China 20132018.

TripAdvisor. TripBarometer. Travel Trends 2016. Recuperado de: https://mk0tainsights9mcv7wv.kinstacdn.com/wp-content/uploads/2018/01/Global-ReportUS-Travel-Trends-TripBarometer-2016.pdf

Yepes Piqueras, Víctor (1999). Las playas en la gestión sostenible del litoral. Cuadernos de Turismo, 4, 89-110. Recuperado de: https://revistas.um.es/turismo/article/view/22881

Vera Rebollo, J.Fernando y Baños Castiñeira, Carlos.J (2010). Renovación y reestructuración de los destinos turísticos consolidados del litoral: las prácticas recreativas en 
la evolución del espacio turístico. Boletín de la Asociación de Geógrafos Españoles, 53, 329-353.

Recuperado

de: https://www.researchgate.net/publication/47757539_Renovacion_y_reestructuracion_de_los_ destinos_turisticos_consolidados_del_litoral_Las_practicas_recreativas_en_la_evolucion_del_esp acio_turistico

Villaécija, Raquel (4 de septiembre de 2019). ¿Por qué España es el destino turístico más competitivo del mundo? El mundo. Recuperado de: https://www.elmundo.es/economia/2019/09/04/5d6f722bfc6c836d6b8b4661.html

Vizcaíno Ponferrada, $\mathrm{M}^{\mathrm{a}}$ Luisa (2016). Nuevas potencias turísticas. International Journal of Scientific Managment Tourism, 2 (2), 491-513. Recuperado de: https://dialnet.unirioja.es/servlet/articulo?codigo $=5665891$

Ye, Jiawen (28 de julio de 2017). The Increasing number of Tourists in Croatia caused by the popularity of Game of Thrones Television Series (《权力的游戏》热播带动取景地旅游业, 克罗地 亚等地游客大增). The paper. Recuperado de: https://www.thepaper.cn/newsDetail_forward_1740639 